Bull. Mater. Sci., Vol. 1, No. 2, October 1979, pp. 79-93, (C) Printed in India.

\title{
Alpha-Quartz 2. Crystal chemistry, and nature and distribution of impurities
}

\author{
PRASENJIT SAHA and TARUN BANDYOPADHYAY \\ Central Glass and Ceramic Research Institute, Calcutta 700032
}

MS received 2 November 1978

\begin{abstract}
Crystal chemistry of alpha-quartz is discussed in relation to the nature, concentration and distribution of the common impurities. Two schemes for incorporation of impurities in the host structure, viz., the charge compensation model for untwinned natural quartz, and the broken-bond model for synthetic quartz to accomodate excess impurity residue after charge compensation, are critically reviewed. Another model for the presence of Al-H defects independent of alkali association in natural quartz is suggested. It is pointed out that the growth pressure influences the nature and distribution of impurities as well as generation of planar and line defects in synthetic quartz. It is also established that mechanical $Q$ (which is a measure of the acoustic loss) of synthetic crystals grown at low pressure deteriorates with increase in impurity content in excess of what is required for satisfying the charge compensation rule.
\end{abstract}

\section{Introduction}

Alpha-quartz, which has a three-dimensional array of linked $\mathrm{SiO}_{4}$ tetrahedra, has a compact structure (see figures $1 \mathrm{a}$ and $1 \mathrm{~b}$ ). $\dot{\dagger}^{\dagger}$ Also there are only two sites for interstitial non-framework ions, atoms or molecules. They are the interlinked hexagonal channels along the $c$-axis (figure 1a) and $a$-axes (figure $1 b$ ). The $a$-axes channels are most densely spaced in the (0001) plane, and then in the $z\{01 \overline{1} 1\}$ planes for the $\mathrm{P} 3_{2} 21$ enantiomorph (the situation is analogous to the $\mathrm{P} 3_{1} 21$ enantiomorph except for the absolute orientations of the $\mathrm{SiO}_{4}$ tetrahedra); however, the layers composed of parallel $a$-axes channels are adjacent for $z\{01 \overline{1} 1\}$, but are separated by an intervening non-channel layer for the $(0001)$ plane. From the crystallographic standpoint, a regular arrangement of interstitial atoms, which is quite probable on the unsaturated growing surfaces of a synthetic crystal, is more likely to give rise to sheet-like impurity layers in the (0001) and $z\{01 \overline{1} 1\}$ planes for both the enantiomorphs.

$\dagger$ Figures $1 \mathrm{a}$ and $1 \mathrm{~b}$ of this paper are the same as figures $1 \mathrm{a}$ and $1 \mathrm{~b}$ of Saha et al (1979), i.e., they are the $(0001)$ and $(2 \overline{1} \overline{1} 0)$ projections of the structure of alpha-quartz, $\mathrm{P}_{2} 21$. Unless otherwise stated, all subsequent alpha-quartz diagrams of this paper depict the $\mathrm{P}_{2} 21$ enantiomorph. 


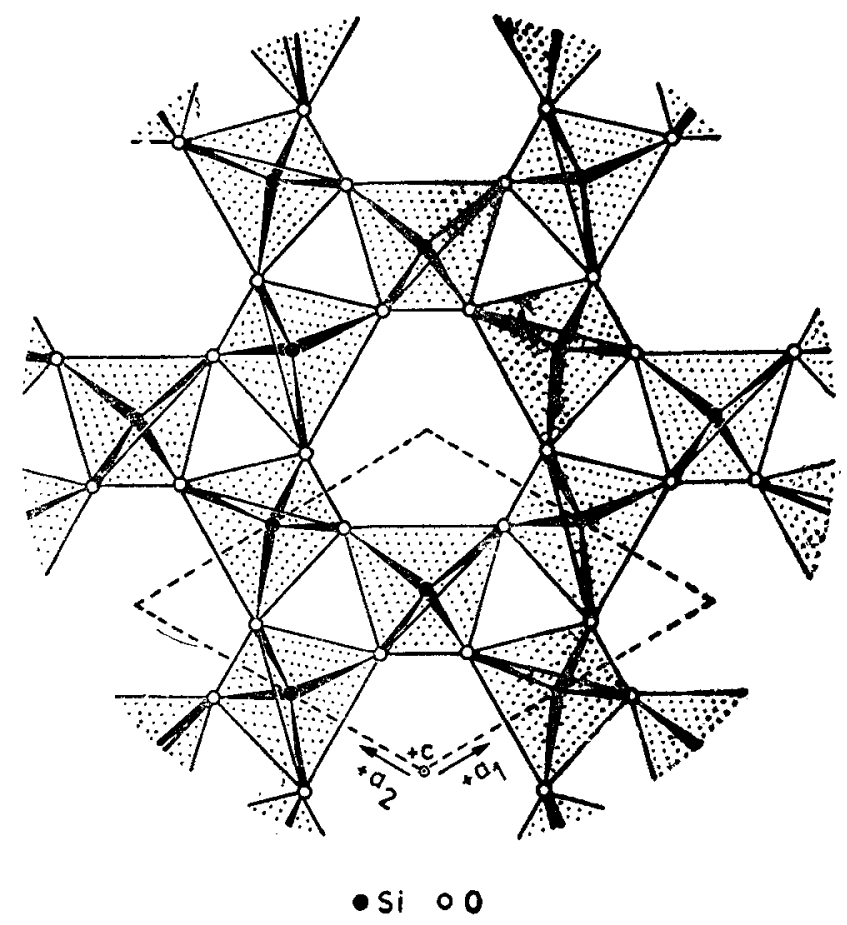

Figure 1(a). (0001) projection of the structure of alpha-quartz $\left(\mathrm{P3}_{2} 21\right)$ showing hexagonal channels along $c$-axis.

\section{Impurities of alpha-quartz}

The impurities commonly found in alpha-quartz are $\mathrm{H}, \mathrm{Li}, \mathrm{Na}$ and $\mathrm{Al}$, and all of them are in ppm range. Bambauer (1961) had summarised previous data on concentration of impurity elements in different varieties of alpha-quartz, and the commonly occurring varietjes of untwinned natural quariz were classified into ordinary quartz consisting of rock crystal (clkar natural quartz) and smoky quartz, and lamellar quartz. Lamellar quartz was defined as a rock crystal with a mimetic structure formed by lamellae of lower symmetry. However, the lamellae which are similarly oriented do not originate from twinning and are not related to twinning (Bambauer 1961; Bambauer et al 1963). Table 1 presents results obtained by Bambauer, as well as data collected by him from literature which includes impurities other than $\mathrm{H}^{*}, \mathrm{Li}^{+}, \mathrm{Na}^{+}$and $\mathrm{Al}^{3+}$.

Untwinned amethyst is extremely rare and totally devoid of hydrogen impurity. In fact, an amethyst crystal containing $<2 \mathrm{H} / 10^{6}$ Si was used by Bambauer (1961) as a reference plate for quantitative estimation of hydrogen by the infrared technique.

Quite distinct from this class of alpha-quartz single crystals is the group containing a substantial number of planar and line defects, namely, optically twinned natural quartz including most of the amethysts (Brunner et al 1961), and synthetic quartz. In the former category, the discontinuity is across the twinning plane (a $\{1120\}$, Saha et al 1979), and in the latter, it is mostly across the cell-wall 


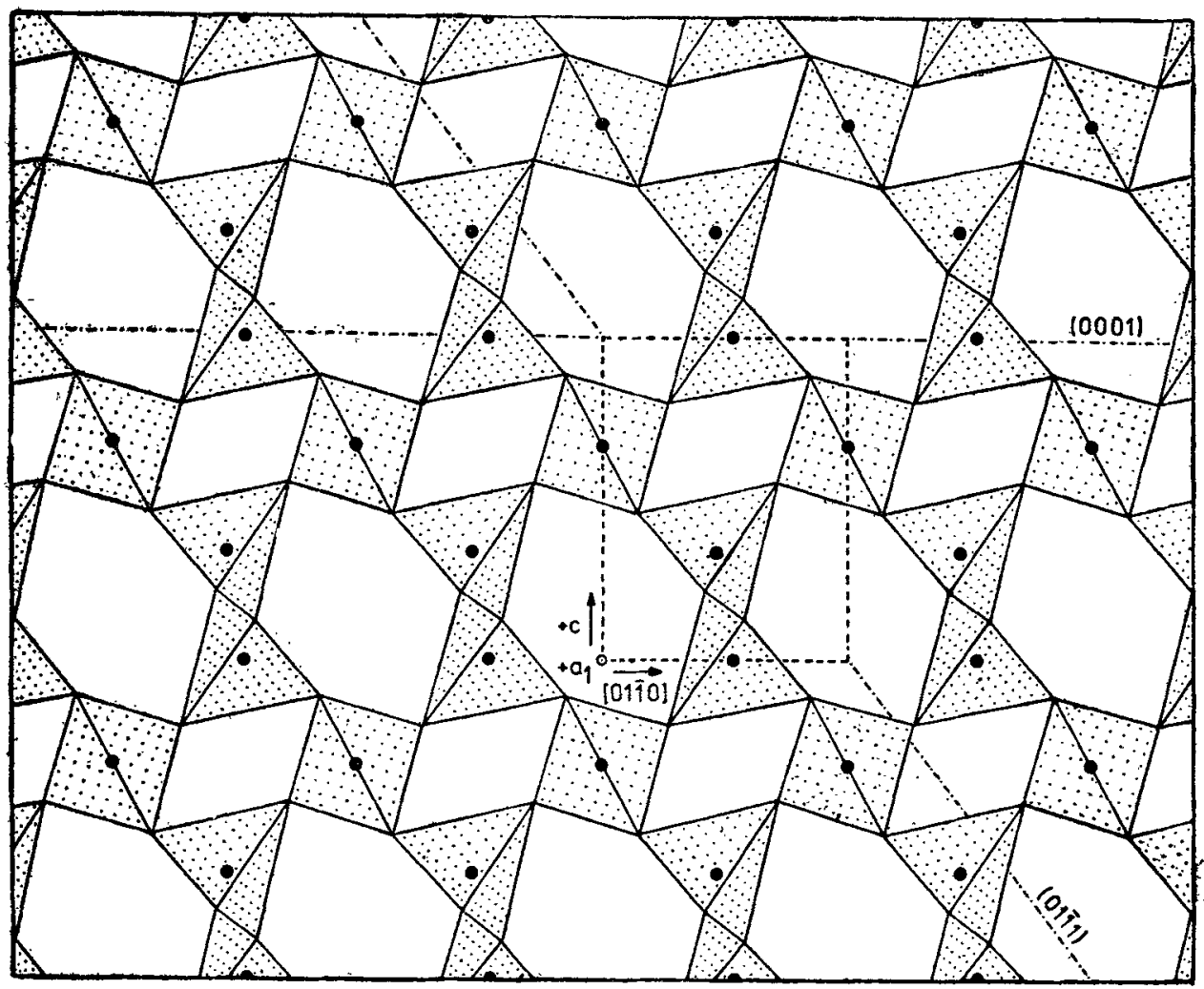

Figure 1(b). (2ÎI0) projection of the structure of alpha-quartz $\left(\mathrm{P}_{2} 21\right)$ showing hexagonal channels along $a$-axes.

Table 1. Concentration of impurities per $10^{6}$ atoms of silicon.

\begin{tabular}{lccccc}
\hline $\begin{array}{l}\text { Variety of alpha- } \\
\text { quartz (Bambauer } \\
\text { 1961) }\end{array}$ & $\mathrm{H}^{*}$ & $\mathrm{Li}^{+}$ & $\mathrm{Na}^{+}$ & $\mathrm{Al}^{3+}$ & Others** \\
\hline $\begin{array}{l}\text { Rock crystal and } \\
\text { smoky quartz }\end{array}$ & $\mathrm{ND}^{+}$ & $0-450$ & $0-80$ & $30-2700$ & $55-421$ \\
Rock crystal & $1-55$ & $10-105$ & $<2-30$ & $30-140$ & $\mathrm{ND}$ \\
Smoky quartz & $2-22$ & $2 \cdot 5-37$ & $\sim 1-15$ & $13-60$ & $\mathrm{ND}$ \\
Lamellar quartz & $35-1200$ & $105-1250$ & $18-40$ & $300-2350$ & $\mathrm{ND}$ \\
\hline
\end{tabular}

+ ND-Not determined.

* See appendix.

** Others include $\mathrm{Rb}, \mathrm{Cs}, \mathrm{Cu}, \mathrm{Ag}, \mathrm{Mg}, \mathrm{Ca}, \mathrm{Ba}, \mathrm{Ge}, \mathrm{Ti}, \mathrm{Fe}, \mathrm{Mn}$ and $\mathrm{Cr}$. 
boundaries. Both groups are usually characterised by a high H-content, comparable in magnitude to that of lamellar quartz (see table 1). Their infrared spectrum in the region $3100-3700 \mathrm{~cm}^{-1}$ closely resembles each other (see appendix).

\section{Chemical considerations}

Figure 2 is a plot of the available data on impurity content of the two groups on logarithmic scales. The diagonal line represents the relation $\mathrm{Al}=\Sigma(\mathrm{H}+$ $\mathrm{Li}+\mathrm{Na}$ ), required for charge compensation after silicon substitution by aluminium impurity. Optically twinned natural quartz, including most of the amethysts, are not plotted since the amethysts are known to contain appreciable amounts of iron. Kats (1962) analysed an amethyst containing $348 \mathrm{Fe}^{3+} / 10^{6} \mathrm{Si}$, and considered it to be a typical value.

Figure 3 gives the dimensions of the channel openings of alpha-quartz. The peripheral oxygen atoms of the channels (ionic radius $=1 \cdot 35 \AA$; Shannon 1976) have been drawn as parts of the circumscribing $\mathrm{SiO}_{4}$ tetrahedra. An inscribed circle normal to the $c$-axis channel openings, being the cross-sectional area of the end-toend free space of the $c$-axis channel, would be approximately $0.85 \AA$ in diameter, and that normal to the $a$-axes channels approximately $0.75 \AA$ in diameter, which are about half the ionic diameters of the alkali impurity ions. Approximate sizes of some of the impurities of alpha-quartz are indicated at the top of figure 3 in terms of their Van der Waals radius $(H=1 \cdot 2 \AA$, Pauling 1960$)$ or ionic radii ( $\mathrm{Na}^{+}$ $=1.02 \AA, \mathrm{Li}^{+}=0.76 \AA$, both in six-fold coordination, Shannon 1976). Aluminium has not been included since it is not likely to be found in non-framework interstitial positions.

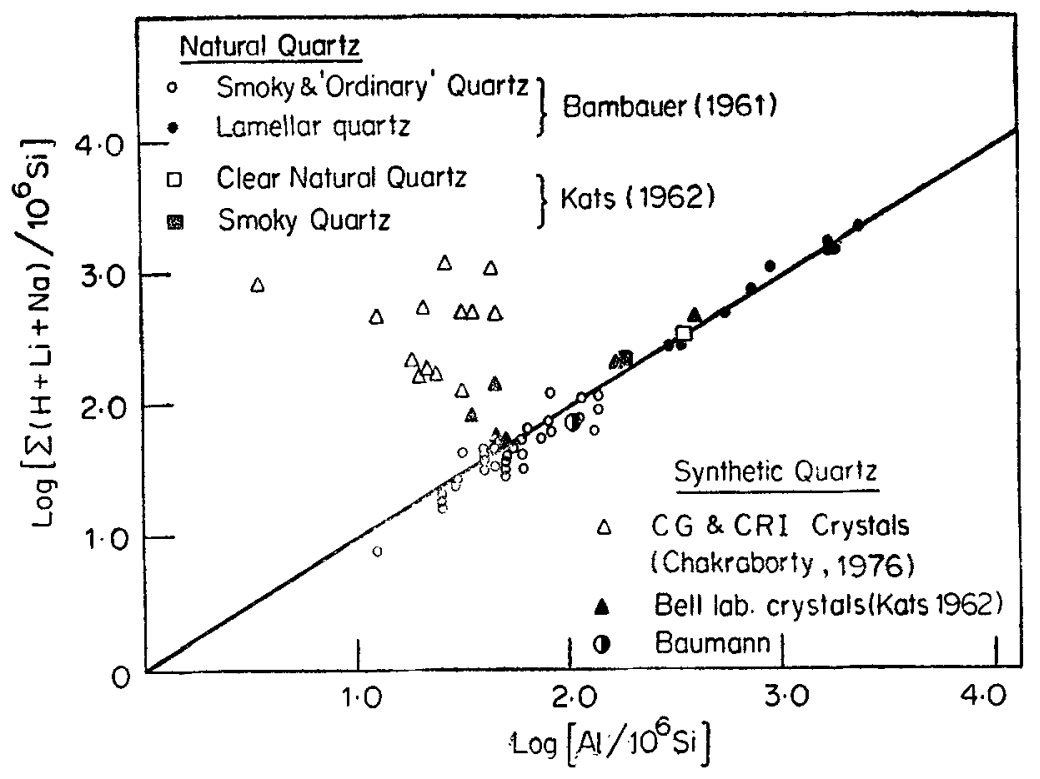

Figure 2. Hydrogen and alkali impurity contents plotted against aluminium impurity in different varieties of natural and synthetic quartz. Logarithmic scales. 


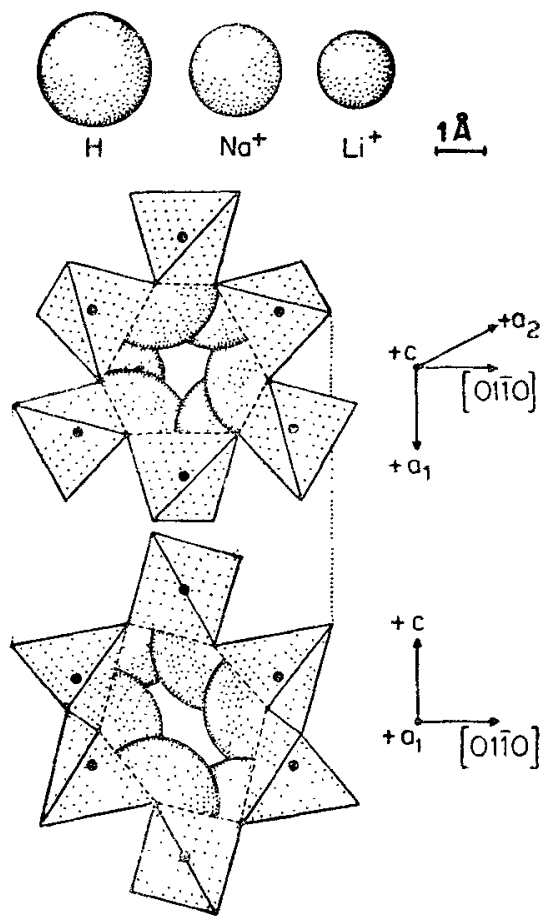

Figure 3. Diagrammatic sketches of the free end-to-cnd openings of $c$-axis and $a$-axes channels of the ideal structure of alpha-quartz, and dimensions of the common impurity elements.

Use of Van der Waals radius in figure 3 for hydrogen impurity merits further discussion, especially since Kats (1962) has apparently assumed a much lesser ionic (?) radius (ca. $0 \cdot 30 \AA$ ) to indicate hydrogen impurity in alpha-quartz. There is no reason why a hydrogen atom bonded to a framework oxygen atom should not have an undistorted electron cloud towards the channel side of radius equal to its Van der Waals radius $(1 \cdot 2 \AA)$. An alternative hydrogen bonding on the channel side is ruled out for the ideal structure since this would require more free space in the channel than for the ideal structure and the $\mathrm{H} \cdots \mathrm{X}$ distance of the approximately linear $\mathrm{O}-\mathrm{H} \cdots \mathrm{X}$ configuration would be approximately $1 \cdot 70 \AA$ (for $X$ to be oxygen; Pauling 1960), and another anionic species $X$ will have to be accommodated in the channel. Moreover, from theoretical considerations based on the shortest $\mathrm{O}-\mathrm{O}$ distance $(3.32 \AA)$ between oxygen ions of different $\mathrm{SiO}_{4}$ tetrahedra of alpha-quartz, and frequency shift associated with $\mathrm{O}-\mathrm{H}$ stretching vibration, Kats (1962) using the Lippincott and Schroeder's curve came to the conclusion that hydrogen bonding in alpha-quartz is unlikely, and hence the $\mathrm{O}-\mathrm{H}$ groups are free.

Notwithstanding the large size of the hydrogen atom depicted in figure 3 , perhaps it would not be correct to conclude that fixation of hydrogen atom in interstitial channel positions in the ideal structure would not be possible, since the $\mathrm{O}-\mathrm{H}$ distance in water molecule is only $0.96 \AA$ (Pauling 1960). Assuming that hydrogen is aftached to a framework oxygen in the form of a free $\mathrm{O}-\mathrm{H}$ group, the effective minimum linear space available for hydrogen in the channels, adjacent to the bridging oxygens of the interlinked $\mathrm{SiO}_{4}$ tetrahedra, should be approximately 
$1 \cdot 2-(1 \cdot 35-0.96)=0.81 \AA$, which is similar to the effective free dimensions of the channel openings. Thus, from structural considerations it seems justified to conclude that hydrogen impurity in alpha-quartz can be accomodated in interstitial positions of the ideal structure without causing strain to the lattice.

Table 1 and figure 3 show that the alkali impurities, $\mathrm{Li}^{+}$and $\mathrm{Na}^{+}$, are important constituents of alpha-quartz. However, as pointed out earlier it is difficult to accommodate the alkali ions in channel interstitial positions of the ideal structure. Nevertheless, if instead of the linear void volume inside the $c$-axis channel, we consider the spiral void volume (after taking into cognisance the spiral arrangement of the linked $\mathrm{SiO}_{4}$ tetrahedra), it may perhaps be possible to somewhat accommodate the alkali ions. Buerger (1954) pointed out that there is sufficient space for the smaller lithium ion, but not for $\mathrm{Na}^{+}$and $\mathrm{K}^{+}$. Moreover, the six-fold coordination of alkali impurity ions (and four-fold coordination of $\mathrm{Li}^{+}$under certain circumstances) will have to be satisfied, and for this the aluminium impurity ions will have to be concentrated locally around the alkali impurity ion. Since Loewenstein's (1954) rule prohibits substitution of two aluminium ions in adjacent linked $\mathrm{SiO}_{4}$ tetrahedra, the matter becomes further complicated. A substantial amount of alkali ions in the ideal structure, especially $\mathrm{Na}^{+}$and $\mathrm{K}^{+}$, is therefore likely to cause considerable strain to the lattice. The biaxial lamellae of untwinned lamellar quartz (Bambauer 1961), containing substantial amounts of the alkali impurities, especially lithium $\left(105-1250 \mathrm{Li}^{+} / 10^{6} \mathrm{Si}\right.$; table 1$)$, may have been generated in this fashion.

\section{Structural states of impurities of alpha-quartz}

The most widely accepted mode of incorporation of hydrogen impurity in alphaquartz is as envisaged in scheme (1) given below, involving substitution of aluminium for silicon and alkali association in the interstitial positions of the channels to compensate for the excess delocalised negative charge of the aluminium ion.

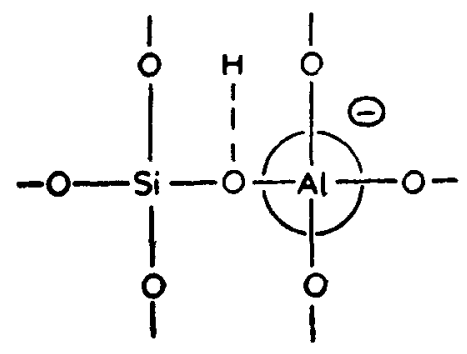

Scherne-1

This charge compensation scheme can be expressed algebraically as follows:

$$
\mathrm{Al}=\Sigma(\mathrm{H}+\mathrm{Li}+\mathrm{Na})
$$

and because of the dative hybrid nature of the linkage the proton is not likely to be strongly attached to the oxygen framework. In fact, the acidity of alpha-quartz is similar to that of methylsalicylate in $\mathrm{CCl}_{4}$, except that the infrared bands are considerably narrower (Kats 1962). Further, it can be seen that this scheme of 
incorporation of impurities would not involve any break in the linkage of the $\mathrm{SiO}_{4}$ tetrahedra of the ideal structure.

Figure 2 shows that incorporation of impurities of rock crystals, smoky quartz and even untwinned lamellar quartz strictly follows this scheme. Impurity contents of some of the synthetic crystals grown at Bell Laboratories as well as by Baumann can also be accounted for by this scheme. However, the hydrogen contents of the crystals estimated by Kats (1962) according to his own formula explained in the Appendix, are lower by a factor of about 2.5 . This point is considered in greater detail in subsequent sections.

The most comprehensive work on the infrared spectra of natural quartz was done by Kats (1962). Approximately 18 anisotropic absorption bands were detected in the $3100-3700 \mathrm{~cm}^{-1}$ region at $78 \mathrm{~K}$. After correcting the spectra for the underlying impurity-independent, low but constant-intensity Si-O overtone and/or combination bands at $3396,3350,3300$ and $3204 \mathrm{~cm}^{-1}$, which were identified by the spectrum of crystal grown in $\mathrm{NaOD}$ solution in $\mathrm{D}_{2} \mathrm{O}$ (by $\mathrm{G} \mathrm{T}$ Kohman of Bell Laboratories) as well as that of a crystal deuterated at $1000^{\circ} \mathrm{C}$ and $25 \mathrm{~atm}$ in $\mathrm{D}_{2} \mathrm{O}$, it was conclusively proved that their intensities were dependent on the concentration of impurities of the specimens, and that they were due to $\mathrm{OH}$-vibration. Various types of electrolysis experiments performed on clear natural quartz and smoky quartz, like exchanging $\mathrm{Li}^{+}$impurity by $\mathrm{Na}^{+}$, exchanged $\mathrm{Na}^{+}$swept out by $\mathrm{K}^{+}$, $\mathrm{Li}^{+}$impurity exchanged by hydrogen, etc., established that the $\mathrm{Li}^{+}$-associated $\mathrm{OH}$ vibration bands occur at 3520,3510,3478, 3440, and $3396 \mathrm{~cm}^{-1}$, and the $\mathrm{Na}^{+}$associated ones at $3556,3534,3513,3453,3400$, and $3382 \mathrm{~cm}^{-1}$ (Kats 1962, table 2), all at $78 \mathrm{~K}$. These observations confirm the validity of the charge compensation rule in clear natural quartz and smoky quartz. Further it was also established, through exchange of original $\mathrm{Li}^{+}$present in a smoky quartz crystal partially by hydrogen and partially by deuterium, that three more weak vibration bands at 3435,3371 , and $3111 \mathrm{~cm}^{-1}$ at $78 \mathrm{~K}$ are due to $\mathrm{Al}-\mathrm{H}$ defects which are independent of alkali concentration, and two of them, namely, those at 3435 and $3371 \mathrm{~cm}^{-1}$ originate from Fermi resonance.

Stepwise heating experiments performed on a predominantly $\mathrm{Li}^{+}$-impurity containing clear natural quartz and the corresponding spectra at $78 \mathrm{~K}$ indicate that all the $\mathrm{Li}^{+}$-associated $\mathrm{OH}$-bands decrease in intensity and finally disappear in the temperature interval $800^{\circ} \mathrm{C}-1000^{\circ} \mathrm{C}$, and concurrently the $\mathrm{Al}-\mathrm{H}$ defect bands attain maximum intensity at $1000^{\circ} \mathrm{C}$. Thereafter, the Al- $\mathrm{H}$ defect bands gradually decrease in intensity in the temperature interval $1000^{\circ} \mathrm{C}-1400^{\circ} \mathrm{C}$, but residual bands are still detectable in the $1400^{\circ} \mathrm{C}$ spectrum. On heating the specimen further at $1000^{\circ} \mathrm{C}$ in $\mathrm{H}_{2} \mathrm{O}$ vapour for $200 \mathrm{hr}$ at $25 \mathrm{~atm}$, the $\mathrm{Al}-\mathrm{H}$ defect bands increase in intensity, becoming comparable to the specimen heated originally at $1200^{\circ} \mathrm{C}$ (Kats 1962). These experiments suggest that on heating the alkali impurities dissociate with the hydrogen impurities and independently coordinate with oxygens attached to some of the aluminium impurities of the linkages circumscribing the channels. On the other hand, hydrogen gets strongly attached to the oxygen bonded to silicon adjacent to an aluminium impurity, with simultancous development of a local break in the linkage of the $\mathrm{SiO}_{4}$ tetrahedra according to the following scheme (1A).

Three-fold coordination of aluminium has been substantiated in some protonated zeolites (Saha 1977). In fact, below $290^{\circ} \mathrm{C}$ a resonance between scheme (1), 


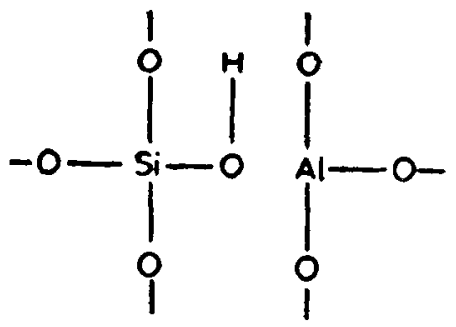

Scherne - 1(A)

the dative hybrid form, and scheme (1A), the no-bond form, has been postulated on firm experimental evidence, the no-bond form predominating increasingly over the other when the zeolite is heated to higher temperatures. Presence of Al-H defect bands in the spectrum of untreated clear natural quartz (Kats 1962) appears to favour this resonance phenomenon. The extremely localised discontinuities, however, are not likely to significantly affect acoustic loss property of the crystals.

Other schemes have been developed to explain colour centres produced when specimens of alpha-quartz are exposed to ionising radiation, in terms of trappedhole centres in the two slightly shorter ligands (GS centres) surrounding each substitutional aluminium impurity ion (O'Brien 1955; Schnadt and Schneider 1970). However, analysis of this work is beyond the scope of this paper.

The scatter for the second group of crystals in figure 2, namely, synthetic quartz, seems to be more pronounced for the crystals developed at this laboratory (called CGCRI crystals) than for the Bell Laboratories crystals, and for such cases

$$
\mathrm{Al} \ll \Sigma(\mathrm{H}+\mathrm{Li}+\mathrm{Na}) \text {, }
$$

i.e., a substantial amount of hydrogen and the alkali impurities is left over after compensating for substitutional aluminium.

The synthetic crystals have been separately plotted in figure 4 . Only the alkali impurities have been plotted against aluminium in figure 4 (b), and it can be seen that all the CGCRI crystals and two crystals developed at Bell Laboratories contain more alkali than that required to satisfy the charge compensation rule (eq. 1). Figure 4 (c) indicates that in CGCRI crystals, barring a single exception, hydrogen alone is much in excess of that required for the charge compensation scheme.

Scheme 2 was originally proposed by Scholze (1959) and Adams and Douglas (1959) to account for OH-vibration bands in silica glass, and adopted by Brunner et al (1961) for optically twinned lamellar quartz including twinned amethyst, and by Kats (1962) for synthetic quartz to account for excess hydrogen:

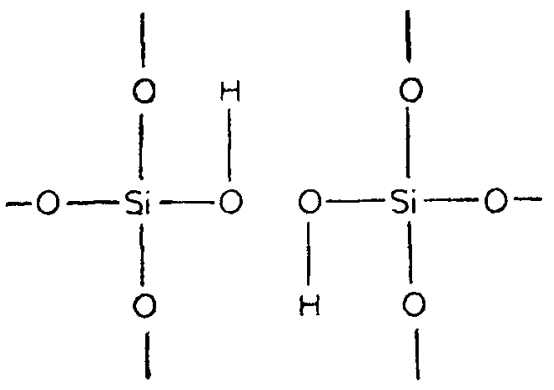

Scheme - 2 

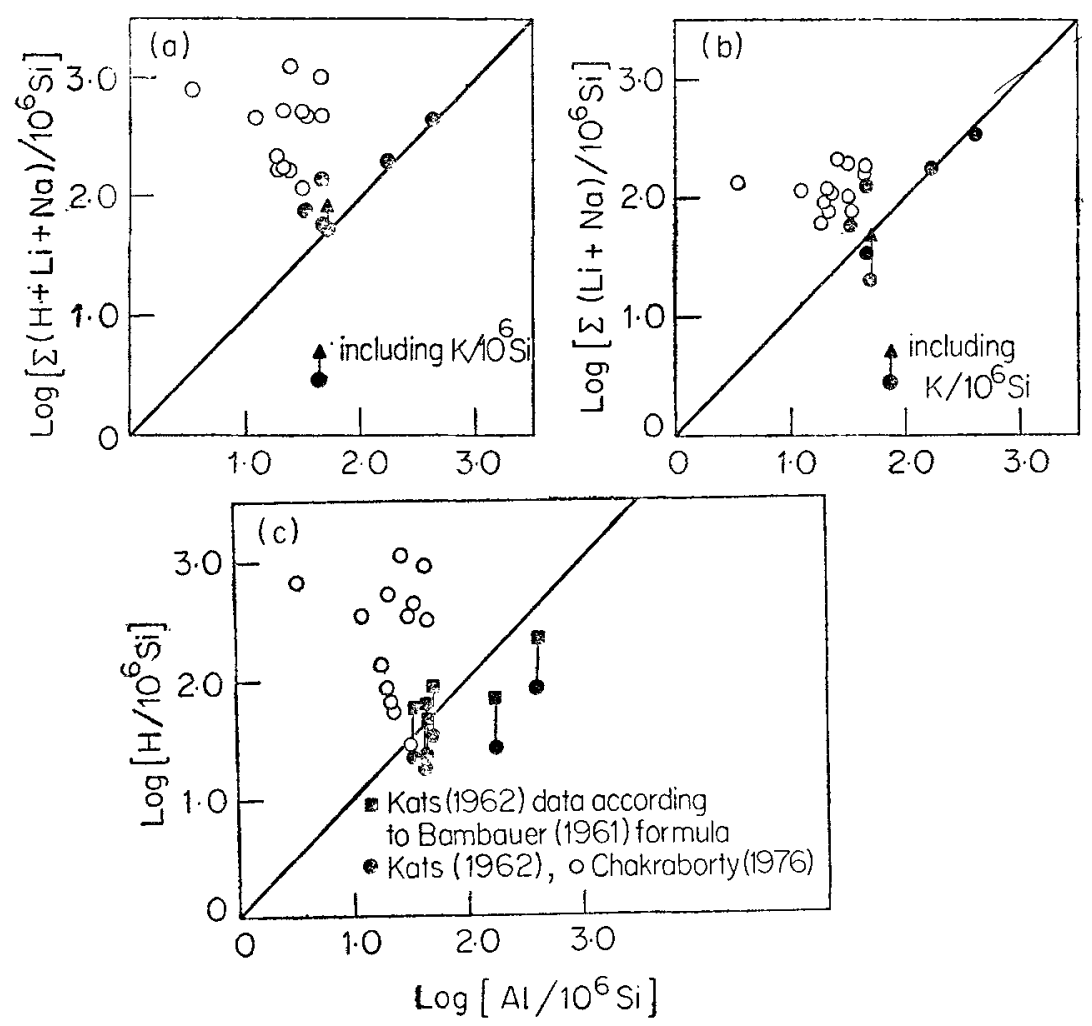

Figure 4. Graphs of aluminium impurity of synthetic quartz plotted against other impurities. Logarithmic scales. (a) Total hydrogen and alkalis vs aluminium. (b) Total alkalis vs. aluminium. (c) Total hydrogen vs, aluminium. Kats (1962) data for hydrogen converted according to Bambauer (1961) formula (see Appendix).

According to scheme 2 not only should a defect develop adjacent to each pair of hydrogen impurity sites (due to a break in the linkage of $\mathrm{SiO}_{4}$ tetrahedra), but there should also be two oxygens in place of one at the defect site. Obviously this scheme would be unlikely for the ideal structure, since there is not enough space to accommodate an excess oxygen atom in either of the two channels. However, it appears to be a plausible alternative for the opened-up structure with (i) planar defects like the faults detected by Lang (1967) in natural quartz, and (ii) with dislocations, and with planar defects coplanar with the dislocations like the cell-wall stacking fault type of fault fringes of synthetic quartz (Saha et al 1979). In this case hydrogen will be strongly attached to oxygen framework, and depending upon the extent of incorporation of hydrogen impurity (which will be independent of concentration of aluminium impurity; see Kats 1962) planar or line defects may occur which will adversely affect the acoustic loss property of the crystals.

Kats (1962) has also given some evidence of the presence of LiOH molecules in synthetic quartz crystals. Again, because of spatial restrictions already discussed, alkali hydroxide molecules and $\mathrm{H}_{2} \mathrm{O}$ molecules of synthetic quartz (see appendix) can only be accommodated in planar and line defects of the opened-up structure. These defects would again, as in the case of scheme (2), lower the 
mechanical $Q$ of the synthetic crystals. The areal variation of mechanical $Q$ of synthetic quartz, increasing with increase in dislocation density, as detected by Auvray and Regreny (1973) supports this conclusion (Saha et al 1979).

\section{Dependence of mechanical $Q$ on impurity content}

Although no specific data are available in literature on the dependence of $Q$ on impurity content of natural quartz, it has been stated that $\mathrm{H}$-content of natural quartz is in some cases comparable to that of synthetic quartz, but its $Q$-factor is always higher, and is normally above $3 \times 10^{6}$ (Chakraborty and Lehmann 1976). As a corollary to this it can be surmised that at least for untwinned natural quartz the mechanical $Q$ would be independent of its impurity content, and the facts that discontinuities do not develop in rock crystal (clear natural quartz), in smoky quartz, and even in untwinned lamellar quartz of high impurity content, and that they strictly follow the charge compensation rule (figure 2), tend to support this view.

The mechanical $Q$ of synthetic quartz, on the other hand, has been determined quite precisely. The $Q$-values at $78 \mathrm{~K}$, of Z-zone (1) of twelve out of thirteen CGCRI crystals analysed for impurity content (Chakraborty 1977) are given in figure 5, with total impurity in excess of what is required for charge compensation [equation (1)] plotted against aluminium impurity, both of Z-zone (1) of the crystals (Chakraborty 1976). It can be seen that mechanical $Q$ deteriorates with total excess impurity. There are only two cases of reversals, one of which is minor, and the other, i.e., $Q=0 \cdot 10 \times 10^{6}$ and $Q=0.19 \times 10^{6}$, may be due to

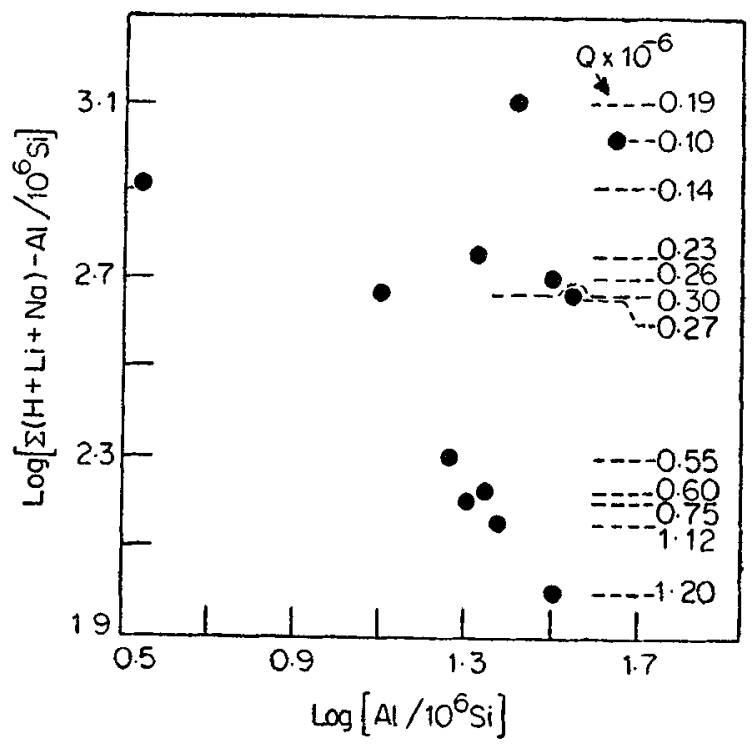

Figure 5. Excess hydrogen and alkali impurities (over aluminium) vs aluminium in CGCRI synthetic crystals, and their mechanical $Q$-values. Logarithmic scaels. 
layered inhomogeneous regions usually found in low quality synthetic quartz crystals (Chakraborty and Saba 1974). Figure 6 indicates the possibility of existence of a break, corresponding to some threshold value of total excess impurity, for transition from a strained ideal structure to one with disconitinuities, but this has to be investigated in further detail.

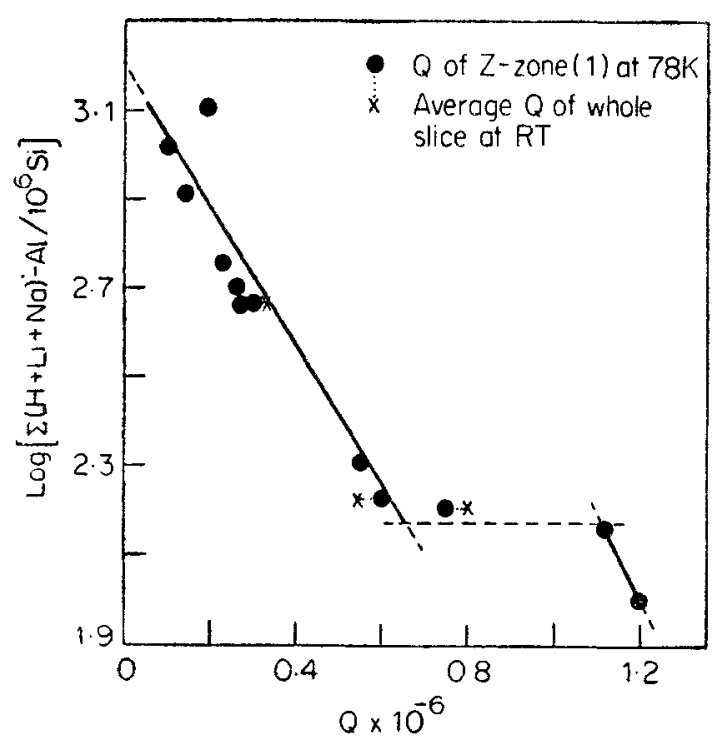

Figure 6. Excess hydrogen and alkali impurities (over aluminium) vs. mechanical $Q$ of CGCRI synthetic crystals. Ordinate in logarithmic scale.

\section{Influence of growth pressure on impurity content and defect structure of synthetic quartz}

Figure 7 is a plot similar to that of figure 2, except that this graph is exclusively for synthetic quartz, and that the H-contents of the Bell Laboratories synthetic crystals have been estimated according to the Bambauer formula, and not according to the Kats formula (see appendix). Three growth pressure zones can be defined, the 5,000-10,000 psi zone crystals containing significant amount of total excess impurity, the 10,000-15,000 psi zone crystals being intermediate in nature, and the 15,000-35,000 psi zone crystals containing impurity slightly in excess of threshold values given by the thick diagonal line (equation (1)). Also it has been reported that at 40,000 psi growth pressure, crystals can be grown at very high growth rates (103 mils/day) in $\mathrm{NaOH}$ solution, and at the same time high mechanical $Q$-values can be obtained $\left(Q=1.4 \times 10^{6}\right.$; Lias et al 1973; table 1, run No. $X-505-2)$. All these observations point to the fact that at high pressures the charge compensation rule is obeyed even in synthetic quartz, and defects due to discontinuities in the ideal structure, like planar and line defects, do not develop so extensively as in the low pressure crystals.

The fact that at low pressure a low growth rate is essential for obtaining high $Q$ crystals (Chakraborty and Saha 1974) indirectly supports this inference. The 


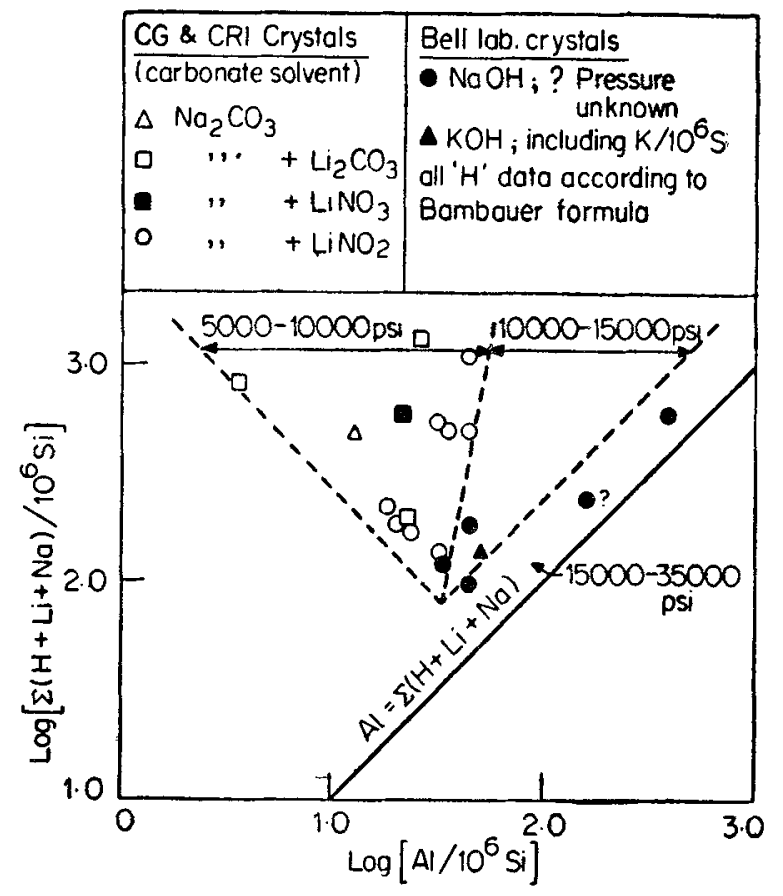

Figure 7. Total hydrogen and alkali impurities vs. aluminium of synthetic crystals, with growth pressure zones imposed on the data. All hydrogen data according to Bambauer (1961) formula. Logarithmic scales. The diagonal line of figures 2, 4 and 7 depicts the charge compensation rule (eq. 1 of text).

highest $Q$-factor obtained for CGCRI synthetic crystals was $1 \cdot 2 \times 10^{6}$, and the growth rate of this crystal along the Z-direction was 27 mils/day (Chakraborty 1977). Significantly, this crystal along with a Bell Laboratories crystal grown in $\mathrm{NaOH}$ solvent at a pressure of only 8,500 psi (growth rate: 8 mils 'day along Zdirection; Kats 1962) has the lowest impurity content of all analysed synthetic crystals (they are the two analyses nearest to the converging tip of the $5,000-10,000$ psi sector of figure 7). Also, the rate of growth of a Sawyer synthetic crystal grown in doped $\mathrm{Na}_{2} \mathrm{CO}_{3}$ solvent at approximately 12,000 psi pressure had to be restricted to 16 mils/day to obtain a $Q$-value of $2.8 \times 10^{6}$ (Lias et al 1973).

\section{Conclusions}

With a view to understand the nature and mode of incorporation of impurities (mainly hydrogen, $\mathrm{Li}^{+}, \mathrm{Na}^{+}$and $\mathrm{Al}^{3+}$ ) in different varieties of alpha-quartz, a critical survey of the available literature data has been carried out. Two groups have been differentiated, the first one comprising rock crystal (clear natural quartz), smoky quartz and untwinned lamellar quartz, and the second one of optically twinned lamellar quartz including twinned amethyst, and synthetic quartz.

Chemical considerations suggest that hydrogen, when altached to oxygen framework in the form of free OH-groups, can be accommodated in the channels of the ideal structure of quartz without causing any strain to the lattice. The same is also true of small amounts of $\mathrm{Li}^{+}$; the only other alkali impurity, namely, $\mathrm{Na}^{+}$, 
and considerable amount of $\mathrm{Li}^{+}$ian only be squeezed into the interstitial positions of the channels of the ideal structure by causing strain to the lattice. Aluminium, of course, can substitute for silicon in considerable quantity, as long as charge balance is maintained. These inferences are substantiated by the mode of distribution of impurities of the first group of crystals. The schemes for incorporation of impurities for this group of crystals are also discussed in the perspective of electrolysis and heating experiments carried out by Kats (1962). However, in many of these experiments the transformation 1emperatures of alpha-quartz $\rightarrow$ beta-quartz and beta-quart $\rightarrow$ tridymite and/or cristobalite had been exceeded, and rence strain due to the first reaction and the submicroscopic formation of separate phases of tridymite and cristobalite due to second can complicate the interpretation of these experiments.

Hydrogen and other alkali impurities may occur in other structural states, e.g., as $\mathrm{LiOH}, \mathrm{NaOH}$ and $\mathrm{H}_{2} \mathrm{O}$ molecules for the second group of crystals including synthetic quartz, and because of their large size they can only be accommodated in discontinuous regions of the opened-up structure. Also for this group, the free OH-groups are much in excess of the H-content required for balancing substitutional aluminium. Such excess free $\mathrm{OH}$-groups occur as broken $\mathrm{SiOH}$ bonds, as found in silica glass, and would give rise to discontinuities in the ideal structure. Manifestations of such discontinuities are the planar defects found in natural quartz, and cell-wall boundaries and line defects in synthetic quartz.

Deterioration of mechanical $Q$ of synthetic crystals has been correlated with increasing impurity in excess of what is required for charge compensation. It has also been shown that impurities associated with planar and line defects, like the broken $\mathrm{SiOH}$ bonds and the alkali hydroxide molecules and water, increase with decrease in growth pressure of the synthetic crystals.

\section{Appendix}

Hydrogen impurity in alpha-quartz is likely to exist in different structural states, and hence the ionic representation would not be meaningful in this context.

Brunner et al (1961) and Bambauer (1961) used the following formula to determine the hydrogen impurity content of alpha-quartz using the infrared method:

$$
c=\frac{2}{3} \frac{\int E d v}{d} \frac{f}{a_{m}}\left[\mathrm{H} / 10^{3} \mathrm{Si}\right]=2 \cdot 11 \mathrm{~K}\left[\mathrm{H} / 10^{5} \mathrm{Si}\right],
$$

where $c$ is the concentration of hydrogen impurity per $10^{6}$ silicon atoms; the factor $2 / 3$ takes care of the anisotropy of the $\mathrm{OH}$ absorption; $K$ is the integral absorption $=\left(\int E d v\right) / d ; d$ is the thickness of the sample; $E$ is the absorbance $\left[\log _{10}\right.$ $\left.\left(I_{0} / I\right)\right], f$ is the conversion factor from moles/l to atoms $/ 10^{6} \mathrm{Si}\left(=\rho .10^{6} / 60=\right.$ 44,400 , where $\rho=2 \cdot 66$, the density of alpha-quartz), and the molar absorption coefficient $\left(a_{m}\right)$ for the integral absorption was determined to be $14,000(\mathrm{~cm} / \mathrm{gm}$ atom). Kats (1962) used the following formula to estimate the hydrogen concentration of alpha-quartz, based on a model of $O-H$ groups bonded to substitutional aluminium ions (since only three main bands at 3435, 3371 and 3311 $\mathrm{cm}^{-1}$ of the infrared spectrum, established by him to be due exclusively to Al-H defects, were utilised for calculating the total integral absorption):

$$
c=2.16 \cdot 10^{16} k\left[\mathrm{H} / \mathrm{cm}^{3} \quad \mathrm{SiO}_{2}\right]=0.81 \mathrm{~K}\left[\mathrm{H} / 10^{6} \mathrm{Si}\right] .
$$


(Kats designated the concentration of hydrogen impurity as $N_{\mathrm{H}}$, which, for conformity with (A1), has been changed to $c$ bere).

Apart from the fact that the Kats formula (A2) is based on an aluminium substitution model, there are two further difficulties associated with its applicability. Firstly, the formula is valid for unpolarised light incident in the direction of the $c$-axis. A correction for anisotropy, as carried out by Brunner et al (1961) and Bambauer (1961), would result in a decrease in the coefficient of the Kats formula, and as it is, this coefficient is already lower than that of the Bambauer formula (A1) by a factor of about $2 \cdot 5$. Furthermore, Kats himself had pointed out that especially for synthetic quartz, the bonding of hydrogen must be different and that his formula (A2) should contain another unknown constant.

Another point in favour of using the Bambauer formula (A1) is that the value of molar absorption coefficient $(14,000 \mathrm{~cm} / \mathrm{gm}$ atom) measured and included in their formula is intermediate between those of water and ice (Scholze 1959) and similar to that of OH-groups in silica glass (Scholze 1960). Hence, it would be reasonable to assume that values obtained by using this formula (A1) would give the hydrogen impurity content of the crystals irrespective of the structural state of hydrogen.

Synthetic quartz invariably exhibits a broad isotropic absorption band underlying the sharp anisotropic absorption bands in the $3100-3700 \mathrm{~cm}^{-1}$ region (Kats 1962; Chakraborty 1977). However, this underlying band is not such an important feature of the Bell Laboratories synthetic crystals analysed by Kats as compared to that of the CGCRI synthetic crystals analysed by Chakraborty. It contributes heavily to the hydrogen impurity content of the CGCRI crystals, and in an extreme case, to the extent of $96 \%$ (Chakraborty 1977) ! In another case, its contribution was estimated to be about $57 \%$ of the total hydrogen content of $359 \mathrm{H} / 10^{6} \mathrm{Si}$. This leaves no doubt whatsoever that molecular $\mathrm{H}_{2} \mathrm{O}$ and alkali hydroxide molecules ( $\mathrm{LiOH}$ and $\mathrm{NaOH}$ ) are present in appreciable quantity in the CGCRI synthetic crystals. All these analyses were carried out on spectra taken at $78 \mathrm{~K}$.

Brunner et al (1961) detected a broad isotropic band in the $3100-3700 \mathrm{~cm}^{-1}$ region in two types of natural quartz crystals, namely, optically twinned lamellar quartz (as distinct from lamellar quartz defined in the text, which is untwinned), and twinned amethyst. Both were found to have a high H-content, as distinct from clear natural quartz or rock crystal, smoky quartz and untwinned amethyst, all having a low $\mathrm{H}$-content. Twinned amethyst, again, was found to have a sharp anisotropic absorption band at $3600 \mathrm{~cm}^{-1}$ (RT spectrum) superimposed on the broad isotropic band (cf. characteristic sharp anisotropic band at $3590 \mathrm{~cm}^{-1}$ in the RT spectrum of synthetic quartz, shifted to $3585 \mathrm{~cm}^{-1}$ at $78 \mathrm{~K}$ ). From the appearence of XOH-and $\mathrm{H}_{2} \mathrm{O}$-combination bands at $4500 \mathrm{~cm}^{-1}$ and at $5200 \mathrm{~cm}^{-1}$, respectively, in the spectrum of twinned amethyst, where $\mathrm{X}$ stands for $\mathrm{Si}, \mathrm{Al}, \mathrm{Fe}$, etc., Brunner et al (1961) conclude that $\mathrm{OH}$ group bonded to silicon, and $\mathrm{H}_{2} \mathrm{O}$, are present in those crystals. They estimate that about $25-50 \%$ of the total $\mathrm{H}$ content of the crystals is molecular $\mathrm{H}_{2} \mathrm{O}$.

\section{Acknowledgement}

The authors are indebted to the Director, for his kind permission to publish this paper. 


\section{References}

Adams R V and Douglas R W 1959 J. Soc. Glass Technol. 43147

Auvray P and Regreny A 1973 Bull. Soc. Fr. Mineral. Cristallogr. 96207

Bambauer H U 1961 Schweiz. Mineral, Petrogr. Mitt. 41335

Bambauer H U, Brunner G O and Laves F 1963 Schweiz. Mineral. Petrogr. Mitt. 43261

Brunner G O, Wondratschek H and Laves F 1961 Z. Elecktrochem. 65735

Buerger M J 1954 Am. Min. 39600

Chakraborty D 1976 J. Cryst. Growth 36188

Chakraborty D 1977 On the influence of environmental parameters on growth and properties of quartz single crystals Ph.D. Dissertation, Jadavpur University, Calcutta

Chakraborty D and Lehmann G 1976 J. Solid State Chem. 17305

Chakraborty D and Saha P 1974 Indian J. Phys. 48439

Kats A 1962 Philips Res. Rep. 17 133, 201

Lang A R 1967 Proc. International Conf. on Crystal Growth, Boston USA., cd. H S Peizer (Oxford: Pergamon Press)

Lias N C, Grudenski E E, Kolb E D and Laudise R A 1973 J. Cryst. Growth 181

Loewenstein W 1954 Am. Min. 3992

O'Brien M C M 1955 Proc. R. Soc. London A.231 404

Pauling $\mathrm{L} 1960$ The nature of the chemical bond $3 \mathrm{rd}$ edition (Cornell University)

Saha P 1977 Trans. Indian Ceram. Soc. 3699

Saha P, Annamalai N and Bandyopadhyay T 1979 Mater. Sci. Bull. 115

Schnadt R and Schneider J 1970 J. Phys. Kondens. Materie. 1119

Scholze H 1959 Glastech, Ber. 32 81, 142

Scholze H 1960 Fortschr. Mineralog. 38122

Shannon R D 1976 Acta Cryst. A32 751 